\title{
Primer informe de leucismo en la paloma de collar Streptopelia decaocto (Columbiformes), especie exótica en México
}

\author{
Armando J. Contreras Balderas ${ }^{1} \&$ Gorgonio Ruiz Campos ${ }^{2}$ \\ 'Laboratorio de Ornitología, Facultad de Ciencias Biológicas, Universidad Autónoma de Nuevo León. Apdo. Postal 425, San Nicolás de los Garza, \\ Nuevo León, México, 66450; arcontre@fcb.uanl.mx \\ ${ }^{2}$ Laboratorio de Vertebrados, Facultad de Ciencias, Universidad Autónoma de Baja California. Apdo. Postal 233, Ensenada, Baja California, \\ México, 22800.
}

Recibido 19-IX-2010 Corregido 8-XI-2010 Aceptado 19-XI-2010

\begin{abstract}
Firstreportofleucisminthe doveStreptopeliadecaocto(Columbiformes), an introduced species in Mexico. The dove Streptopelia decaocto is a Palearctic species that has become established in Mexico. Leucism is a partial loss of pigmentation. Here, we report the first leucistic individual of this dove, from El Rosario de Abajo, Ensenada, Baja California, Mexico, November $29^{\text {th }}, 2009$ ( $30^{\circ} 02^{\prime} 24^{\prime \prime} \mathrm{N}$ y $\left.115^{\circ} 44^{\prime} 24^{\prime \prime} \mathrm{W}\right)$.
\end{abstract}

KEY WORDS

Streptopelia decaocto, pigmentation, leucism, México.

\section{RESUMEN}

La paloma de collar, Streptopelia decaocto, es una especie originaria del Paleártico occidental, introducida en México. El leucismo es una pérdida parcial de pigmentación. Aquí informamos del primer individuo leucístico en México, visto en El Rosario de Abajo, Ensenada, Baja California, México, el 29 de noviembre del $2009\left(30^{\circ} 02^{\prime} 24^{\prime \prime} \mathrm{N}\right.$ y $\left.115^{\circ} 44^{\prime} 24^{\prime \prime} \mathrm{W}\right)$.

PALABRAS CLAVE

Streptopelia decaocto, pigmentación, leucismo, México.
La paloma de collar Streptopelia decaocto, es una especie originaria del Paleártico occidental, hallada desde las Islas Británicas, sur de Escandinavia, y occidente de Rusia, sur y sureste de Europa, hasta Egipto, y sur de Asia Oriental,a Birmania y Sri Lanka.

Las poblaciones europeas representan una expansión relativamente reciente, tal vez resultado de introducciones. Introducida y establecida en América (Islas Bahamas) en 1974 (A.O.U. 1998), se ha extendido y colonizado diferentes países de América (Smith 1987).

Las aberraciones cromáticas generalmente se deben a la expresión de un gen recesivo que se manifiestan en las poblaciones silvestres, aunque estos patrones de coloración alterados podrían estar generados por factores externos, tales como la dieta (Sage 1962, Clapp 1974, Buckley 1982); también puede influir algún tipo de infección o enfermedad o por lesión en los folículos celulares (PhiIlips 1954); en general se deben a expresiones de genes mutantes (Baker 1991, van Grouw 2006). Las formas más conocidas son la pérdida total (albinismo) o parcial (leucismo) de pigmentación.

El leucismo se ha documentado bastante bien en diferentes grupos de aves, como se reporta en diferentes trabajos siguientes. Se cita un individuo recolectado en Massachusetts de Pinicola enuclator eschatosus con las rectrices y parte de las primarias de color blanco, mencionando este cambio como una dilución de la coloración normal (Snyder 1968).

En Anas discors cerca de Manitoba, Canadá, se capturaron tres jóvenes con cambio de coloración en el cuello, presentando plumas blancas con diferente ancho de banda de esta aberración cromática; los criterios de diferentes autores incluyen el origen genético, sin especificar una causa en especial (Trauger 1976).

En Bristol County, Massachusetts, se observó un individuo totalmente blanco excepto los ojos pardos, 
de Thryothorus ludovicianus, reportando observaciones adicionales por otras personas en lugares cercanos (Seneca 1985).

Un caso de leucismo parcial en Puffinus opisthomelas se reporta en el sur de California y se menciona que esto causa confusión en la identificación de algunas especies marinas (Garrett 1990).

Un individuo de garza con coloración inusual, correspondiendo a Butorides virescens en el sur de California se descubre y aunque se menciona que diversas especies de garzas son blancas completamente, esta presentaba coloración en el primer plano de la cabeza que permitieron su identificación (Garrett 1994).

Las aberraciones cromáticas se observan de diferentes tipos frecuentemente en especies gregarias o sedentarias que suelen presentar endogamia, esto lo mencionan en el reporte de leucismo en Agelaius thilius (Mermoz \& Fernández 1999). En varios individuos de Phoebastria nigripes y P. immutabilis en localidades de California y Hawaii, se reporta leucismo, mencionando también algo de confusión en la identificación, no sólo por el leucismo, sino también por la hibridación entre estas especies (McKee \& Pyle 2002).

Se menciona que durante varias semanas de junio del 2002, detectó un individuo leucístico de Tringa semipalmata en California (Collins 2003). También en un individuo de Tiaris olivacea en Cuba se reporta el leucismo y se menciona que el origen del cambio de coloración posiblemente sea genético (Acosta Broche 2005). También se fotografió un Podiceps nigricollis en Mono Lake, California, en octubre del 2006, mencionando la importancia de la fotografía para documentar estos casos (Blumin 2007). En Podiceps nigricollis se reporta información adicional de leucismo en la misma localidad de Mono Lake, la proporción de esta anomalía cromática por lo menos en este zambullidor es de 1:100,000-150,000 (Jehl 2007). Se reporta un individuo leucístico de la loica común (Sturnella loyca) en Buenos Aires, Argentina (Morici 2009).

\section{METODOLOGÍA}

Los organismos fueron fotografiados y no capturados. La observación fue directa en campo y se identificó siguiendo el criterio actual aplicado en la ornitología (Field Guide of the Birds of North America de National Geographic 2006). Su distribución original y arreglo sistemático y nomenclatural, fue siguiendo el criterio de la Sociedad de Ornitólogos Estadounidenses (A.O.U. 1998).

\section{RESULTADOS}

Hemos observado la paloma de collar Streptopelia decaocto en el norte de Mexico en diferentes estados, donde se reproduce libremente, siendo ya una especie feral que rápidamente extiende su área de distribución, no solo en áreas urbanas, sino también silvestres.

En una visita realizada al poblado El Rosario de Abajo, Ensenada, Baja California, México $\left(30^{\circ} 02^{\prime} 24^{\prime \prime} \mathrm{N}\right.$ y $115^{\circ} 44^{\prime} 24^{\prime \prime}$ W), el 29 de noviembre del 2009, hallamos un individuo de Streptopelia decaocto con leucismo (Figs. 1 y 2).

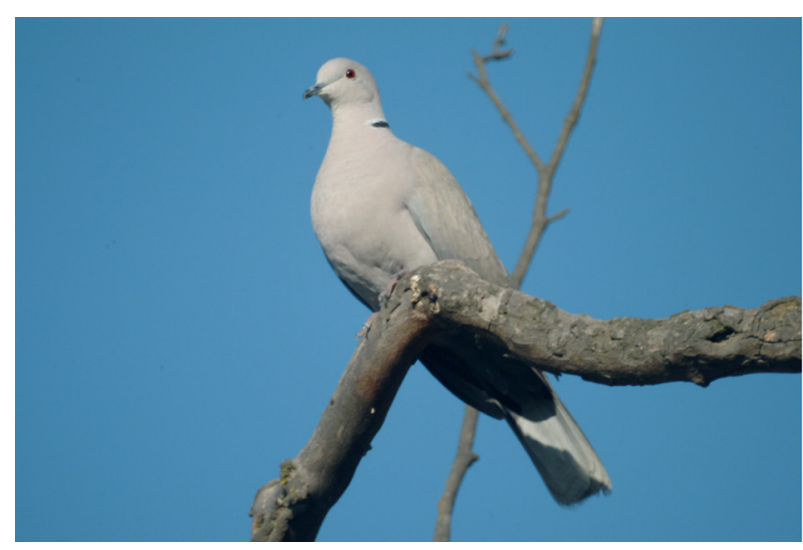

FIG. 1. Coloración normal de Streptopelia decaocto. El Rosario de Abajo, Ensenada, Baja California, México, 29 de noviembre de 2009.

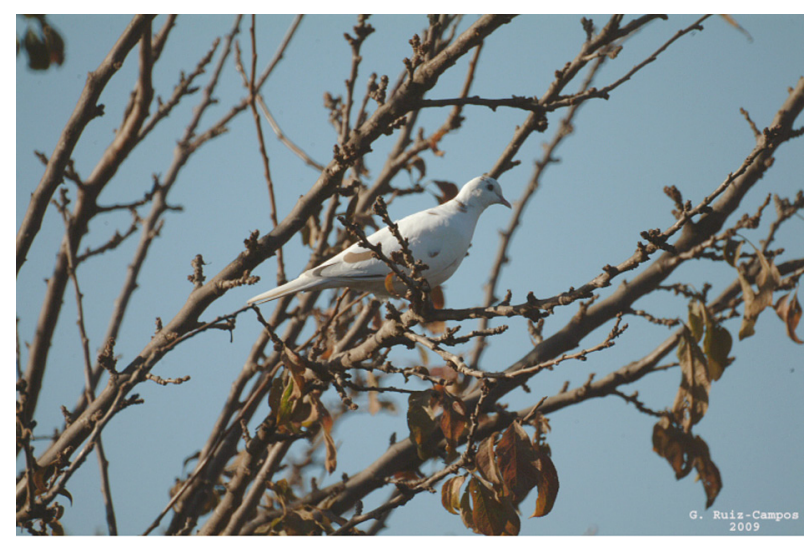

FIG. 2. Coloración leucística en Streptopelia decaocto. El Rosario de Abajo, Ensenada, Baja California, México, 29 de noviembre 2009. 


\section{DISCUSIÓN}

Aunque se trata de un problema genético (Trauger 1976, Mermoz \& Fernández 1999, Acosta Broche 2005), se requiere incrementar los estudios para ver si tiene una causa exclusivamente genética o si está involucrado algún otro factor relacionado con factores ambientales y biológicos que permitan expresarse a este gen.

La aberración cromática puede considerarse una desventaja para el individuo, pues es más fácilmente localizable por el depredador (Torres \& Franke 2008).

Por las referencias bibliográficas y consultas realizadas, este trabajo viene a ser el primero que reporta el leucismo en esta especie de paloma. Aunque se trata de una especie exótica en México, lo trascendente es la presencia de la aberración cromática y no el estatus geográfico de la misma, ya que los diferentes reportes solo incluyen especies nativas.

\section{REFERENCIAS}

Acosta Broche, L. 2005. Primer caso conocido de leucismo parcial en Tiaris olivacea en Cuba. Huitzil 6:14-15.

American Ornithologist's Union (A.O.U.). 1998. Check-list of North American Birds. American Ornithologists' Union and Allen, Lawrence, Kansas, USA.

Baker, A. 1991. A review of New Zealand ornithology, p. 1-67, In: D.M. Power (ed) Current Ornithology. Plenum, New York, USA.

Blumin, L. 2007. Leucistic Grebe at Mono Lake - An identification challenge. Western Birds 38: 64-68

Buckley, P. 1982. Avian genetics, p. 21-110, In: M. Petrak (ed) Diseases of cage and aviary birds. Lea \& Febiger, Philadelphia, USA.

Clapp, R. 1974. Albinism in the Black Noddy (Anous tenuirostris). Condor 76: 464-465.
Collins, Ch. 2003. Featured photo a Leucistic Willet in California. Western Birds 34:118-119.

Garrett, K. L. 1990. Leucistic Black-vented Shearwaters (Puffinus opithomelas) in Southern California. Western Birds 21:69-72.

Garrett, K. L. 1994. A White Green Heron in Southern California. Western Birds 25:198-200.

Jehl Jr., J. R. 2007. Additional notes on leucistic Eared Grebes at Mono Lake. Western Birds 38:289-292.

McKee, T. \& P. Pyle. 2002. Plumage variation and hybridization in Black-footed and Laysan Albatrosses. North American Birds 56:131-138.

Mermoz, M. \& G. Fernández. 1999. Albinismo parcial en el Varillero Ala Amarilla (Agelaius thilius). Nuestras Aves 40: 20-21.

Morici, A. 2009. Leucismo en Loica común (Sturnella loyca) en el Sudoeste de la Provincia de Buenos Aires, Argentina. Nuestras Aves 54: 8.

Phillips, A. R. 1954. The cause of partial albinism in a Great-tailed Grackle. Wilson Bulletin 66:66.

Sage, B. L. 1962. Albinism and melanism in birds. British Birds 55: 201-225.

Seneca, J. 1985. A record of extreme leucos in the Carolina Wren. Wilson Bulletin 97: 244.

Smith, P. 1987. The Eurasian Collared-Dove arrives in the Americas. American Birds 41:1371-1379.

Snyder, D. 1968. A leucistic Pine Grosbeak. Wilson Bulletin 80: 333-334.

Torres, M. \& I. Franke. 2008. Reporte de albinismo en Podiceps major, Pelecanus thagos y Cinclodes fuscus. Revista Peruana de Biología 15:105-108.

Trauger, D. L. (1976). Plumage aberranty in Blue-winged Teal. Auk 93: 646-650.

van Grouw, H. 2006. Not every white bird is an albino: sense and nonsense about color aberrations in birds. Dutch Birding 28: 79-89. 
